\title{
In praise of posters
}

\author{
Can you imagine scientific meetings without poster sessions?
}

The busiest - and loudest — areas of any conference are most likely to be the poster sessions. This is surely testament to the power of the humble poster: they are the places to see the newest science and talk to the people who actually do the work in the lab. The Nature Chemistry editors are frequently to be found inspecting and discussing posters (with or without a beer in hand...) that catch their eye at the conferences they attend throughout the year.

Not every scientist attending a meeting can expect to have a slot to speak in - otherwise the average ACS national meeting would just about finish in time for the next one to start - but most of them can present posters. This makes a poster session a very democratic marketplace: almost anyone can choose to present their wares, but your potential audience has only a limited time resource to spend on a wide choice.

\section{A key attraction of poster sessions is the chance to talk to the people who actually performed the experiments.}

But once upon a time there must have been meetings without posters. So when was the first poster and who came up with the idea? Sadly, it looks as though history (or at least, as it is indexed by Google, Web of Science and other such databases) has not recorded the exact moment for us to celebrate. As far as we can tell, however, the idea originated in Europe, perhaps because the range of languages spoken meant it would be a good idea to have a session where delegates could absorb information in a non-native language at their own pace. The phenomenon was only reported in North America in 1974 at the Biochemistry/ Biophysics Meeting in Minneapolis ${ }^{1,2}$. Not that Americans were slow to embrace the visual, however. The American Chemical Society then introduced poster sessions for the fall national meeting, in Chicago in $1975^{3}$, a move that resulted in some 41 presentations (take a bow, Divisions of Chemical Education and Inorganic Chemistry) ${ }^{4}$. What's more, the session was seen as a 'trail blazer's.
Since those early days of poster pioneers, the rise of personal computing alongside desktop publishing and graphical design software has further driven the evolution and development of posters. Of course, having the right tools to hand does not guarantee that the perfect poster will be produced every time. Everyone has seen examples that break one, several, or all of the design rules, often resulting in cluttered layouts, unreadable text, badly displayed graphics and so on. Indeed, it's not hard to find examples of professional graphic designers poking fun at their more academic colleagues' efforts ${ }^{6}$.

So what makes a good poster? Fortunately for the more graphically challenged presenter, there are books ${ }^{7}$, websites $^{8}$, blogs ${ }^{9}$ and even a Flickr photo group $^{10}$ devoted to academic posters. From the combined experience of the Nature Chemistry team (which includes one first and two third prizes from our student days), we can also offer some advice. Clarity and content are key. Can all the text be read from a reasonable distance? Imagine that your poster is the highlight of the session: your ideal collaborator (or an interested editor) could be struggling to make out your conclusions at the back of the adoring crowd! Balancing the amount of content is probably the hardest part of any poster design. Too much, and the design can be become cluttered, busy and off-putting. Too little, and the poster may appear lightweight and not worthy of attention.

As with any presentation meant for an external audience, considering who makes up that audience and suitably tailoring your poster is critical. The amount of background material needed for a small subject-specific meeting will be very different from that needed for an ACS meeting with many thousands of attendees. Consider whether you need to include every last piece of data or supporting work - you don't need to tell the whole story on paper because you'll be there to fill in the gaps. When presenting your poster to other delegates, finding out what level of background knowledge they have will mean you pitch it at the right level. This also has the potential to create a dialogue more meaningful than the presenter simply going through a well-practised spiel.

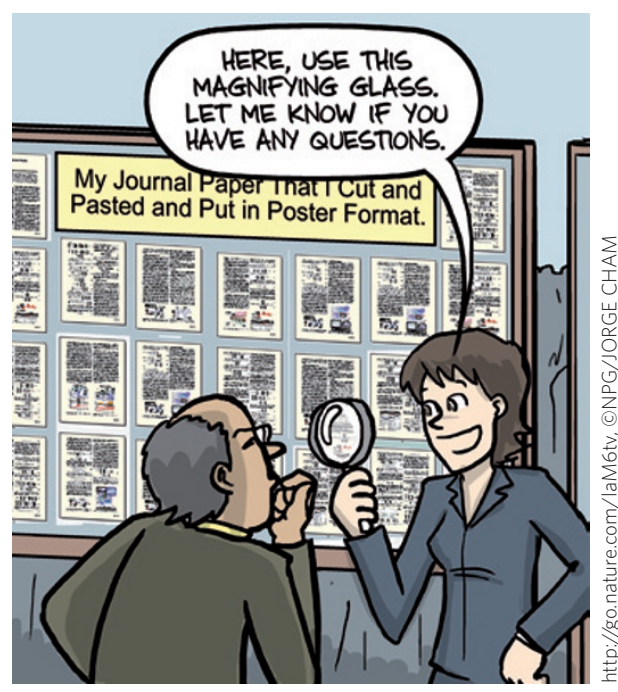

As mentioned in the first paragraph, one of the key attractions of most poster sessions is the opportunity to talk to the people - typically graduate students or postdocs - who have actually performed the experiments, but do not always have the chance to speak. Getting the inside track on how the project really developed in the lab, rather than how it is presented in the finished research article, can often be fascinating, and many hidden stories often emerge. As networking events, poster sessions are unequalled at most scientific meetings: relaxed and full of opportunities to bump into people you didn't realize were even there. People who might make the ideal advisor for that post-doctoral position you were looking for - and vice versa.

Posters are often a scientist's first presentation or even publication, and can represent the first step on their journey to public scrutiny, feedback and peer review. This alone should be enough to raise them in people's estimation, and not be treated as an afterthought by conference organisers or attendees.

\footnotetext{
References

1. Science 184, 1361 (1974).

2. Chem \& Eng News 52, 14 (1 July 1974).

3. Chem \& Eng News 53, 20 (14 April 1975).

4. Chem \& Eng News 53, 19 (8 September 1975).

5. Chem \& Eng News 53, 5 (3 November 1975).

6. http://observatory.designobserver.com/entry.html?entry=4917

7. Gosling, P. J. Scientist's Guide to Poster Presentations (Springer, 1999).

8. http://colinpurrington.com/tips/academic/posterdesign

9. http://betterposters.blogspot.com/

10. http://www.flickr.com/groups/postersessions/pool/ with/4072353403/
} 